\title{
Single and Combined Effects of Sympathetic and Parasympathetic Activity on Perceptual Sensitivity and Attention.
}

Davydov, D.M., \& Shapiro, D. (1999). Single and combined effects of sympathetic and parasympathetic activity on perceptual sensitivity and attention. Journal of Russian and East European Psychology, 37, 68-90.

Dmitry M. Davydov ${ }^{\mathrm{a}}$ and David Shapiro ${ }^{\mathrm{b}}$

a Serbsky National Research Center for Social and Forensic Psychiatry, Moscow, Russia.

${ }^{\mathrm{b}}$ Department of Psychiatry, University of California, Los Angeles

Keywords: Pulse volume, Pulse rate, Sympathetic, Parasympathetic, Perceptual sensitivity, Attention

Running title: Autonomic activity and perception

\section{Address for correspondence}

Dmitry M. Davydov,

Laboratory for Clinical Neurophysiology,

Serbsky National Research Center for Social and Forensic Psychiatry,

23 Kropotkinsky pereulok, Moscow, 119839, Russia.

E-mail: dadimati@mail.ru 


\begin{abstract}
Pulse rate and cephalic pulse volume were recorded from 17 male and 37 female normal subjects during performance of an attentional task under high and low stress conditions. Verbal threshold (perceptual sensitivity) and word recognition (attention) were assessed using a visual verbal recognition task. Subjects were divided at the median for pulse rate and pulse volume during baseline, instruction, and task periods and grouped in terms of these two measures to represent different patterns of parasympathetic (vagal) and sympathetic activity. Analysis of variance was used to examine the effects of gender, stress condition, and autonomic pattern on autonomic activity, perceptual sensitivity, and attentional performance. Gender showed significant effects for pulse rate with higher scores for women during the instruction and task periods. High stress reduced perceptual sensitivity and resulted in better attentional performance. Whereas stress-induced sympathetic activity was related to low perceptual sensitivity and good attentional performance, high sympathetic in conjunction with low vagal baseline activity predicted relatively high perceptual sensitivity and poor attentional performance. Low or high baseline activity in both autonomic systems predicted low perceptual sensitivity and good attentional performance. Predictions of perception and attention can be improved by examining the effects of patterns of sympathetic and parasympathetic activity.
\end{abstract}




\section{Introduction}

Measures of cardiovascular functions are considered highly relevant to the processes involved in sustained attention (e.g., Matthews et al., 1990; Suess et al., 1994). Porges (1992) proposed that attentional processing is an ergotropic process, resulting in disruption of normal homeostatic processes and a loss of parasympathetic tone. Resting heart period and an index of vagal activity derived from sinus arrhythmia during a rest period prior to a continuous performance task were found related to attentional performance on the task (Suess et al., 1994). It was hypothesized that high resting cardiac vagal activity is associated with good attentional capacity (Porges, 1992; Suess et al., 1994). Munro et al. (1987), on the other hand, reported that the greater the degree of task-induced sympathetic nervous system arousal (measured by frequency of spontaneous skin conductance responses) the less of a decrease in perceptual sensitivity over time during an attentional task. Subjects who demonstrated a high frequency of spontaneous electrodermal responses (high sympathetic arousal) while at rest ("electrodermal labiles") showed good performance on an attentional task (Dawson et al., 1990). Such lability reflects the ability to allocate information-processing capacity to stimuli that are to be attended (Katkin, 1975; Schell et al., 1988).

The above findings indicating that a high level of resting parasympathetic and of resting sympathetic activity can each facilitate attention suggest an apparent contradiction, as the two systems are usually seen as acting in opposition to one another. However, this latter view is oversimplified as increased vagal activity and increased sympathetic activity can both occur concurrently (De Marinis et al., 1995; Hugdahl, 1996), reflecting independent sources of neural control. Berntson et al. (1996) demonstrated that mental arithmetic was associated with a reciprocal pattern of sympathetic activation and vagal withdrawal. A visual illusion task, however, yielded a distinct mode of vagal activation in the absence of sympathetic change. These varying patterns of autonomic response emphasize the importance of multivariate theories of autonomic control (see Porges, 1995). 
Lacey et al. (1963) formulated the view that different patterns of parasympathetic and sympathetic activity are associated with different kinds of task involvement, based on studies of electrodermal and heart rate responses. They detected concurrent sympatheticlike increases in both measures as well as an increase in the former and a decrease in the latter. Lacey focused on two kinds of interactions associated with autonomic response patterns, one in which attention is directed to an internal task or process (environmental rejection) and one in which attention is directed to an external stimulus (environmental intake). Following Lacey’s formulations (Lacey, 1959; Lacey et al., 1963) and the other research cited, we expect that individual differences in attentional performance should be associated with different patterns of sympathetic and parasympathetic nervous system activity. Sympathetic activity should increase in each type of task involvement, but parasympathetic activity should depend on the specific task requirements. For example, during the 4-s preparatory interval of a reaction time task, a pattern of heart deceleration and a corresponding small increase in blood pressure has been observed (Paller and Shapiro, 1983).

These relationships are further complicated by the fact that resting autonomic activity is a relatively stable trait of the individual (Dawson et al., 1990; Kronholm et al., 1996), which has a genetic origin (Snieder et al., 1997). Baseline or resting autonomic activity is associated with performance on attentional tasks (Katkin, 1975; Schell et al., 1988; Porges, 1992; Suess et al., 1994). Generally, when attention reduction occurs during a task, it is greater in subjects with low sympathetic activity (stabiles) than in subjects with high sympathetic activity (labiles). Thus, the concept of individual differences in sympathetic arousal based on the electrodermal activity model becomes a more general behavioral model of attentional performance.

Other researchers have followed up on the hypothesis that high parasympathetic (vagal) tone is associated with good attentional capacity. Porges and others researchers (e.g., Kalsbeek, 1973; Porges, 1980; Mulder and Mulder, 1981; Porges, 1992) proposed 
hypotheses regarding the link between vagal-mediated changes in heart rate variability and individual differences in attention, meaning that high resting cardiac vagal activity as individual trait is associated with good attentional capacity. For example, Suess et al. (1994) showed that subjects with high resting vagal activity (e.g., slow heart rate) differed from subjects with low resting vagal activity in their performance at the beginning of an attentional task. The authors concluded that a significant positive correlation between resting vagal activity and attentional performance reflects individual differences in ability to sustain attention early in the task. They failed to detect a significant interrelation between cardiac activity and attentional performance during the final stage of the task. The findings of Weber et al. (1994) present a challenge to the vagal tone theory of attentional control by suggesting age changes in attention (counting target stimuli) and phasic heart rate change control that are not associated with a concomitant change in respiratory sinus arrhythmia. Paller and Shapiro (1983) did not find significant correlations between task performance (response latency in a reaction time task) and systolic blood pressure or heart rate changes. They also observed that the blood pressure and heart rate changes were independent of one another, suggesting a dissociation between excitatory sympathetic (alpha-adrenergic innervation of the vasculature) and parasympathetic (cholinergic innervation of the myocardium by the vagus nerve) influences during the task. It is clear from the apparent inconsistencies in these empirical observations and theoretical statements that more research is needed to further our understanding of concurrent sympathetic and parasymapthetic changes in attentional tasks.

The present study had three major objectives. The first was to evaluate the role of parasympathetic and sympathetic activity as correlates of perceptual sensitivity and attentional performance. The second was to determine whether the prediction of sensitivity and performance can be improved by examining the combined effects of parasympathetic and sympathetic activity. The third was to determine the effects of psychosocial stress and gender on various task and autonomic measures. 
We measured changes in pulse volume and pulse rate to assess sympathetic and parasympathetic responses and response patterns. Although psychophysiological research indicates an association between changes in sympathetic activity and effort or strain in cognitive activity (Kagan et al., 1988; Borson et al., 1989; MacDowell and Mandler 1989) and an association between sympathetic activity and decreases in peripheral blood flow (Stone and Hokanson, 1969; Mathews and Lader, 1971; Guyton, 1981), the relation between pulse volume and sustained attention has been less well investigated. Sympathetic nervous system activity was evaluated by skin blood flow (pulse volume), which is reduced via direct sympathetic nerve innervation and via circulating epinephrine and norepinephrine (Guyton, 1981). Parasympathetic nervous system activity was assessed by pulse rate (Suess et al., 1994), because heart rate changes within the normal range are believed to be primarily parasympathetically controlled (Papillo and Shapiro, 1990).

The tasks that have mainly been used to study sustained attention include choice reaction time or tracking tasks, which provide quantitative measures of vigilance (Paus et al., 1997). In the present study, fluctuations in sustained attention or vigilance were assessed with a word recognition task. As discussed in previous papers (Dawson et al., 1989; Filion et al., 1991; Filion et al., 1994), an attention task usually requires subjects continuously to monitor the environment for presence of a target stimulus. In the present investigation, a tachistoscopic method was used to present two unrelated words separated by a short interval of time, and performance was measured by the accurate detection of the targets. It was hypothesized that the difference in first (forward masking) vs. second (backward masking) word detection reflects a difference in attention (see Methods section). This difference in attention may be related to stress or other situational factors or to individual differences in sustained vigilance (Dawson et al., 1990). Performance was assessed as a total score for the whole session.

We also examined thresholds for detecting single words. This measure of perceptual sensitivity is a less complex measure of information processing in contrast to performance 
on the word recognition task. We expected that the relationships between autonomic activity and these two different behavioral measures might differ as a function of the resources needed to perform the task.

Social evaluation threat was used to determine the effects of situational stress on performance and on autonomic responses to the task (Smith et al., 1984; Smith et al., 1997). Social stressors increase vasoconstriction (Smith et al., 1984) and heart rate (Smith et al., 1997). These cardiovascular responses during the social task are similar to effects obtained using nonsocial cognitive or vigilance tasks (Smith et al., 1997). The studies showed that such stress effects on cardiovascular activity were not dependent on gender in any analyses; hence, in the present study, the means presented were collapsed across each factor. By examining the effects of social stress on a vigilance task, we were able to evaluate similarities and differences in behavioral and autonomic responses to the same task under different conditions. Specifically, we wanted to determine the degree to which baseline as compared to activity of autonomic measures during the task predicts differences in sustained vigilance and how these relationships are affected by social stress.

\section{Methods}

\section{Subjects}

The subjects were 17 male and 37 female undergraduate medical students who were randomly assigned to a low stress (13 male, 16 female) or to a high stress (4 male, 21 female) condition. An additional 11 subjects were randomly assigned to a group without transducer attachment to determine whether presence of the forehead transducer had an effect on visual perception. Presence of the forehead transducer did not affect the results. Subjects were studied individually.

Physiological Recording Methods 
Pulse rate (PR) and frontal pulse volume (PV) were recorded with a reflectance photoelectric plethysmographic transducer attached to the central area of the subject's forehead (right above and half way between the the arches of the eyebrows) using AC amplifiers (time constant $=0.03 \mathrm{~s}$ ) on an 8-channel Nihon Kohden multipurpose polygraph (RM-86). The data were displayed on paper.

Although little is known about the relationship between frontal pulse volume and attention, we chose this measure for the following reasons: Frontal PV has been used to estimate orienting, defense, and startle reflexes (Turpin, 1986; Turpin and Siddle, 1983), mechanisms of which are associated with attentional and vigilance processes (Dawson et al., 1990). The frontal area of the brain has been used to obtain indirect estimates of intracranial blood vascular activity (Chance et al., 1993; Okada et al., 1994). The blood supply to this area is affected by the internal and external carotid arteries (Skolnick et al., 1979).

Pulse Volume (PV) and Pulse Rate (PR) were scored by the procedures described in Turpin and Siddle (1983). The number of pulse spikes within each 20-s interval was counted and expressed in bpm. PV was scored by measuring the height of pulse spikes within each interval in mm from the diastolic trough to the systolic peak and transforming it into $\mu \mathrm{V}$. PR and PV were scored and averaged for each 20 sec period (about 12 measures for Session 1 and about 15 for Session 2). This 20-sec interval is the minimum time needed to average effects related to pulse volume itself, respiration, and neuropsychological processes (Moshkevich, 1970). Data from the initial and final baseline periods were averaged to obtain a single mean baseline value for PV and PR (PVb, PRb). This was done because there was no difference in PR and only a slight difference in PV between the two baselines. Moreover, the final baseline was not affected by the stress condition. Mean values were also obtained for the instruction period (PVi and PRi) and for Session 1 (PV1 and PR1) and Session 2 (PV2 and PR2) sessions. In statistical analyses of the findings for 
periods other than the baseline, we used the absolute measure of PV inasmuch as post-hoc analyses using baseline PV as a covariate did not affect the results (see Smith et al., 1984).

\section{Perceptual Sensitivity and Attention Tasks}

Session 1 was used to obtain the visual verbal threshold (perceptual sensitivity), in which ten different words were randomly presented. Each word could be presented more than once. We determined from pilot studies that the repetition of words did not diminish the thresholds or affect the results in Session 2 in which performance was threshold dependent. In Session 2, attentional performance was assessed using 18 pairs of words in more than 18 trials. Each presentation of a word pair constituted a trial. Although word frequency and word length varied widely in the experiment as a whole, no words rarely used in Russian were included, and the words in each pair were comparable in both frequency and length. In Session 1, word frequency was almost identical, and all words were seven letters long. As language constructions are typically grasped when the components are perceived separately and not as a whole, slight differences in word length were not considered critical to the design of the study (Gregory, 1972). Pilot experiments as well as post-hoc analyses of data from the present study showed no correspondence between word frequency and their identification in Session 1 or Session 2.

During both sessions, the words were displayed at the center of a black-and-white display by means of a PDP-compatible computer. All time-dependent parameters of presentation of the words were synchronized to the screen refresh rate of the display. Black words were generated on a gray background fixation box, the length of which corresponded to the length of the word, followed by production of a gray blank mask to eliminate after images, which was active until the next word or word pair was presented. In Session 1, exposure time started at $20 \mathrm{~ms}$ and was increased in increments of $20 \mathrm{~ms}$ until the subject correctly identified three successive words. This exposure time was designated as the visual verbal threshold (VVT), the measure of perceptual sensitivity. In Session 2, each of 
the words in the word pairs was presented at the VVT exposure time. In this session each two-word presentation constituted a trial; the interval between the words of a pair varied from 40 ms up to the interval at which the subject correctly identified a minimum of one word in the pair. For each pair of words the number of trials could be more than one. The interstimulus period for the single words in Session 1 and the intertrial period for the word pairs in Session 2 was $3 \mathrm{~s}$ (Polich et al., 1983). This period was sufficient for the response. During the experiment, subjects were seated in a soundproofed and dimly lit room. Subjects determined how far away from the screen they wanted to be seated for best viewing of the stimuli.

Scores on the visual task performance were averaged and transformed. For purposes of the analysis, an index of attention (ATT) was derived which reflected the detection either of the first or the second word in each pair initially. Since both words were physically similar, followed by masks, and were defined as targets, the subject's attention had to be engaged on the to-be-attended channel. With supraliminal exposure, the subject can detect both words in the forward order or the first word in the pair when detection of the second word is temporally suppressed by forward masking of the first word context (Lukatela et al., 1991). If attention is occupied by other processes and temporarily unavailable for word recognition, then that results in temporal omission (or suppression) of the first word in the pair, which is due to backward masking by the second word context. Since the mechanism of backward masking is connected with a limitation of capacity of the sensory channel for proper representation of the first stimulus (Mesherski, 1982), a backward masking opposite to forward masking is indicated as primarily cortical and useful in assessing aspects of cognitive dysfunction (Schlapfer et al., 1991). Other experiments provide evidence that the improvement in signal detectability under conditions of backward masking is due to enhanced sensory processing (Wolford et al., 1988). In the present study, it was hypothesized that the difference in primarily first (forward masking and forward order of words recognition) vs. second (backward masking and backward order of words 
recognition) word detection reflects a difference in attentional strategy. We assume that detection of the first word indicates superior attentional peformance. An average index of attentional performance for the whole session (ATT) was calculated as follows:

$$
\text { ATT=(n1-n2)/(n1+n2); }
$$

where $\mathrm{n} 1$ and $\mathrm{n} 2$ equal the number of pairs with detection of the first and the second word of the pairs. ATT varied from -1 to +1 , with positive ratios meaning «good» attention.

\section{Procedure}

After the transducers were attached, subjects were asked to sit quietly for $5 \mathrm{~min}$. Physiological data from the last 2 min of this period constituted the initial baseline. Instructions were then given via the display of the computer. All subjects were told that they had to identify and distinguish words and word pairs presented on the screen. Subjects were instructed to name the words in each word pair in the order they were detected. Subjects in the high stress condition were further informed that their performance would be evaluated in terms of the level of intelligence evident in their responses. Subjects in the low stress condition were told that the experiment was concerned with physiological correlates of simple vision; no mention was made of any evaluation whatsoever. The time of this instruction period was about $1 \mathrm{~min}$. Then, Session 1 followed in which the visual verbal threshold was determined (about $4 \mathrm{~min}$ ), followed immediately by Session 2 (attention task) (about $5 \mathrm{~min}$ ). In both high and low stress conditions, the stimuli used were identical. At the end of Session 2, subjects were asked to sit quietly for 2 min while a second baseline physiological recording was made.

The region of rejection for the null hypothesis was set at the $p<.05$ level.

\section{Results}


Effects of Gender and Psychosocial Stress on Perceptual Sensitivity, Attentional Performance, and Autonomic Measures

Prior to analyses of individual differences, the effects of gender and stress on VVT, ATT, and autonomic measures were tested with one-way ANOVAs. Analysis of PR indicated a significant gender effect, such that women had a higher PR during the instruction period and both Session 1 and Session $2(\underline{F}(1,53)=5.57, \underline{\mathrm{p}}<.05 ; \underline{\mathrm{F}}(1,53)=6.24, \underline{\mathrm{p}}<.05 ; \underline{\mathrm{F}}(1,53)=7.33$, p $<.01$, respectively). Gender was not significantly related to VVT or PV (Table 1).

Although women scored higher on ATT, the difference in attentional performance was not statistically significant $(\underline{\mathrm{F}}(1,53)=2.86, \underline{\mathrm{p}}<.10)$. Therefore, further analyses were conducted without consideration of gender effects on VVT and ATT and the means presented in analyses of individual differences were collapsed across this factor.

ANOVA showed that high stress instructions resulted in greater vasoconstriction, however the effect was not statistically significant $(\underline{F}(1,53)=2.94, \underline{p}<.10)$ (see Table 2$)$. Scores of VVT and ATT were significantly lower in the low stress condition $(\underline{F}(1,53)=5.37$, $\mathrm{p}<.05 ; \underline{\mathrm{F}}(1,53)=4.87, \mathrm{p}<.05$, respectively) In general, compared to high stress, low stress tended to result in less sympathetic activation (larger PV amplitude), higher perceptual sensitivity (low VVT), and backward attentional strategy (low ATT) on the task. Stress did not significantly affect PR.

Means for PV, PR, VVT, and ATT calculated separately for Gender and Condition are presented in Tables 1 and 2.

Sympathetic and Parasympathetic Activity as Correlates of Perceptual Sensitivity and Attentional Performance

Subjects were divided at the median for sympathetic and parasympathetic activity during the baseline period (PVb and PRb), the instruction period (PVi and PRi), Session 1 (PV1 and PR1), and Session 2 (PV2 and PR2). Simple one-way ANOVAs of ATT and VVT 
were conducted with each parasympathetic (high vagal activity vs. low vagal activity) and each sympathetic grouping (high sympathetic activity vs. low sympathetic activity). Significant effects for mean ATT were obtained for PVb, PVi, and PV1 $(\underline{F}(1,53)=6.22$, $\underline{\mathrm{p}}<.05 ; \underline{\mathrm{F}}(1,53)=9.08, \underline{\mathrm{p}}<.005 ; \underline{\mathrm{F}}(1,53)=9.08, \underline{\mathrm{p}}<.005$, respectively). High sympathetic activity during baseline (PVb), the instruction period (PVi), and prior to the attentional task (Session 2) predicted a backward strategy of attentional performance. No significant effects were found for PV activity during Session 2 or PR activity during baseline and other periods. Perceptual sensitivity did not show any significant effects.

A two-way ANOVA of Condition X Autonomic Group revealed no significant interactions for any of these measures.

\section{Combined Effects of Sympathetic and Parasympathetic Activity}

Means for PV, PR, VVT, and ATT calculated for each sympathetic/parasympathetic grouping are presented in Table 3. Two-way ANOVAs were performed with sympathetic and parasympathetic baseline activity as independent factors to evaluate their interactive effects on perceptual sensitivity and attentional performance. A significant interaction was obtained for mean VVT $(\underline{\mathrm{F}}(1,53)=4.32, \underline{\mathrm{p}}<.05)$. Although the effect for ATT did not reach the .05 level $(\underline{F}(1,53)=2.80, \underline{p}=.10)$, planned comparison of contrasts revealed that for subjects of Group 2 (Table 3) with high sympathetic and low vagal baseline activity ATT was lower than for subjects in the other autonomic groupings $(\underline{F}(1,50)=3.34, \underline{p}<.10$; $\underline{F}(1,50)=6.02, \underline{\mathrm{p}}<.05 ; \underline{\mathrm{F}}(1,50)=8.07, \underline{\mathrm{p}}<.01$, respectively, see Table 3). Moreover Group 2 had a significantly lower mean VVT than Group $1(\underline{\mathrm{F}}(1,50)=4.42, \underline{\mathrm{p}}<.05)$, which had concurrently high scores for both sympathetic and vagal activity, and a lower mean VVT than Group $4(\underline{F}(1,50)=3.45, \underline{p}<.10)$, which had concurrently low scores for both sympathetic and vagal activity, although the latter difference was not statistically significant. Thus, high sympathetic baseline activity, especially with concurrent low vagal activity, tended to predict high perceptual sensitivity and backward strategy of attentional 
performance. Furthermore when both autonomic activities were concurrently high or low during baseline, perceptual sensitivity was low and dominant attentional strategy was forward masking and forward detection order.

Two-way ANOVAs were also performed with sympathetic and parasympathetic activity during instruction and Session 1 and 2 periods to evaluate their interactive effects on perceptual sensitivity and attentional performance. Although correlations between baseline and on-task autonomic activitites were high, these analyses were conducted to test reliability of the effects. Planned comparison of contrasts revealed that for subjects with high sympathetic and low vagal activity during instructions or Sessions 1 and 2, ATT was significantly lower than for subjects with low sympathetic and high vagal activity $(\underline{F}(1,50)=4.86, \underline{\mathrm{p}}<.05 ; \underline{\mathrm{F}}(1,50)=4.53, \underline{\mathrm{p}}<.05 ; \underline{\mathrm{F}}(1,50)=4.76, \underline{\mathrm{p}}<.05$, respectively). For subjects with high sympathetic and low vagal activity during Session 1, ATT was also significantly lower than for subjects with concurrently low scores for both sympathetic and vagal activity $(\underline{F}(1,50)=5.67, \underline{p}<.05)$. Moreover subjects with high sympathetic and low vagal activity during the instruction period had a lower mean VVT than subjects who had concurrently low scores for both sympathetic and vagal activity $(\underline{F}(1,50)=2.85, \underline{p}<.10)$, but the difference was not statistically significant. Thus, high sympathetic activity with concurrent low vagal activity during the instruction period predicted high perceptual sensitivity and backward strategy of attentional performance. Furthermore, in contrast to the former group, low sympathetic with concurrent high vagal activity during instructions and the sessions periods predicted forward strategy of attentional performance. When both autonomic activities are concurrently low during instruction period, perceptual sensitivity was low.

Three-way ANOVAs (Condition X Sympathetic Group X Parasympathetic Group) revealed no significant interactions with Condition for any of these measures, and thus the means presented in analyses of individual differences were collapsed across this factor. 


\section{Discussion}

In agreement with the findings of Smith et al. (1984), who used digital pulse volume as an index of anxiety in their study, cephalic pulse volume was responsive to the threat manipulation during the instruction period. Greater vasoconstriction was shown during the high stress compared to the low stress instructions. Perceptual sensitivity and attentional performance were also affected by the different levels of threat. Scores of perceptual sensitivity and attentional performance were lower in the low stress condition. Since a variety of psychological processes are associated with sympathetic nervous system activity and levels of circulating catecholamines, it is clear that these measures (pulse volume, sensitivity, performance) need to be evaluated in the context of additional measures if they are to be interpreted as indices of stress or anxiety. Cardiovascular measures were also affected by gender. Women had a higher pulse rate than men during the instruction period and during the task itself.

With regard to baseline autonomic activity, differences between subjects in sympathetic but not parasympathetic activity predicted attentional performance. Furthermore, high sympathetic in conjunction with low vagal baseline activity predicted high perceptual sensitivity and preference of backward attentional strategy, whereas stressinduced sympathetic activity was related to lower perceptual sensitivity and preference of forward attentional strategy. However, when the two autonomic systems are both high or the two systems are both low in baseline activity, the result was low perceptual sensitivity and a forward attentional strategy. Thus, when subjects had high sympathetic baseline activity, the additional factor of high or low concurrent parasympathetic baseline activity predicted, respectively, low or high perceptual sensitivity and forward or backward attentional strategies. Therefore, in subjects with high baseline sympathetic activity, behavior-autonomic interrelations may be interpreted from the standpoint of the concept of parasympathetic control of perceptual sensitivity and attentional performance (Porges, 1992). In subjects with low parasympathetic baseline activity, differences in high or low 
sympathetic baseline activity predicted, respectively, high or low perceptual sensitivity and backward or forward attentional performance. Thus, in subjects with low baseline vagal activity behavior-autonomic interrelations may be examined from the standpoint of the concept of sympathetic control of perceptual sensitivity and attentional performance. Consequently, behavior-autonomic interrelations are under control of both branches of the autonomic nervous system, but the predictive value of each system depends on the associated level of baseline activity of the other system.

Additional analyses of patterns of autonomic activity showed that high sympathetic activity with concurrent low vagal activity during the instruction period predicted high perceptual sensitivity and backward attentional strategy. In contrast, low sympathetic with concurrent high vagal activity during the instruction and task periods predicted forward attentional strategy. When both autonomic activities were concurrently low during the instruction period, perceptual sensitivity was low. Thus, attentional performance was under the control of both sympathetic and parasympathetic systems, but perceptual sensitivity was primarily affected by the sympathetic system. A decrease in sympathetic activity with a concurrent increase in vagal activity may induce a transition from the forward to the backward strategy in attentional performance. An increase in sympathetic activity with unchanged low vagal activity may predict increased perceptual sensitivity.

Both words of each pair in our study were physically similar, followed by masks, and were defined as targets. With supraliminal exposure, the subject detected both words in the forward order or the first word in the pair when detection of the second word is temporally suppressed by forward masking of the first word context. When attention was occupied by other processes and temporarily unavailable for word recognition, then that resulted in temporal omission of the first word in the pair (or order of words recognition was backward), which is due to backward masking by the second word context. Since the mechanism of backward masking is connected with a limitation of capacity of the sensory channel for proper representation of the first stimulus (Mesherski, 1982), a backward 
masking opposite to forward masking is indicated as primarily cortical and useful in assessing aspects of cognitive dysfunction (Schlapfer et al., 1991). Other experiments provide evidence that the improvement in signal detectability under conditions of backward masking is due to enhanced sensory processing (Wolford et al., 1988). Thus, it may be hypothesized that the difference in forward masking and forward order of recognition vs. backward masking and backward order of recognition reflects a difference in attentional strategy. It may be assumed that the former (forward strategy) indicates a high level and the latter (backward strategy) a low level of information processing and attention.

In distinguishing attentional and arousal domains, Dawson et al. (1994) interpreted a trait physiological (sympathetic) indicator of hyporesponsiveness (skin conductance orienting responses) as an attentional deficit rather than a deficit of physiological arousal. Suess et al. (1994) found that high vagal activity derived from cardiac activity related to high attentional performance on a task. Lacey (Lacey et al., 1963) detected concurrent sympathetic-like increases in sympathetic and parasympathetic activity, as well as an increase in the former and a decrease in the latter. In the first case, attention was directed to an internal task or process (environmental rejection), and in the second case, attention was directed to an external stimulus (environmental intake). Following Lacey's formulations (Lacey, 1959; Lacey et al., 1963), sympathetic activity should increase in each type of task involvement, but parasympathetic activity should depend on the specific task requirements. The present study showed that the interrelationship of both sympathetic and parasympathetic activity may predict differences in perceptual sensitivity and attention. In contrast to Lacey's findings and views, we observed other autonomic patterns showing significant relationships to behavioral measures. The pattern with concurrent sympatheticlike increases in both pulse rate and pulse volume during baseline as well as during the task showed consistent effects on the behavioral measures. For Lacey, this pattern is associated with a situation in which attention is directed to an internal task or process (environmental rejection). This conception is supported by the fact that in the present study this autonomic 
pattern was associated with poor performance in a task requiring sustained attention to external stimuli (backward strategy from our hypothesis). But for the same autonomic pattern, perceptual sensitivity for external stimuli was high. This fact indicates that perceptual sensitivity and attention are different behavioral activities that are connected with different brain mechanisms and are also greatly affected by emotional and motivational factors (Davydov and Gavrilenko, in press). We conclude that interrelations between autonomic activity and behavior cannot be determined by any one single theory of autonomic control of information processing.

If we consider that changes in perceptual sensitivity are associated with general, nonspecific activation and that changes in attention are associated with activation of specific mental processes, we can understand their contrasting relationship with sympathetic and parasympathetic activity. In contrast to the specific effects of parasympathetic activation, sympathetic activation connects with general, non-specific activation of many physiological systems including, for example, the immune system. Thus, by determining how the two systems are interrelated, we can make better predictions of an individual's general readiness to respond as in the case of perceptual sensitivity versus adaptation to the specific requirements of sustained attention or vigilance. In this regard, we should note that in the present study individual diffrences in threshold (sensitivity) and word recognition (attention) were significantly but only weakly correlated $(r=.310, p<.02)$. It is clear from the results of the present study that the relation between each process and autonomic activity is complex and depends on many factors. We speculate that the relation may depend on the source of the stress. Stress may come from an outer or from an inner source. In the present study, the outer stress was produced by instructional set and the inner stress was subject determined and estimated by measures of sympathetic nervous system activity. The outer threat appears to lead to a decrease in perceptual sensitivity along with better attentional performance on a task, whereas the inner process leads to an increase in perceptual sensitivity and poorer attentional performance. Thus, similar increases in 
sympathetic activation derived from different sources may lead to different behavioral changes. If we are to improve our understanding of the role of autonomic nervous system activity in attention and other behaviors, then we need to give more careful consideration to emotional and motivational sources of the autonomic activity as well as the behavior (Davydov and Gavrilenko, in press).

Finally, we should note that we have simplified the fact that sympathetic and parasympathetic activity are complex processes that may be differently illuminated by various physiological measures. In this study, pulse volume and pulse rate were selected to examine how these processes, singly and in combination, affect perception and attention, and it remains to be determined whether the same kinds of results will be obtained with other autonomic measures. 


\section{References}

Berntson, G.G., Cacioppo, J.T., \& Fieldstone, A. (1996). Illusions, arithmetic, and the bidirectional modulation of vagal control of the heart. Biological Psychology, 44, 117.

Borson, S., Barnes, R.F., Veith, R.C., Halter, J.B., \& Raskind, M.A. (1989). Impaired sympathetic nervous system response to cognitive effort in early Alzheimer's disease. Journal of Gerontology, 44, M8-M12.

Chance, B., Zhuang, Z., UnAh, C., Alter, C., \& Lipton, L., (1993). Cognition-activated low-frequency modulation of light absorption in human brain. Proceedings of the National Academy of Sciences, 90, 3770-3774

Davydov, D.M., \& Gavrilenko, A.Y. (in press). Autonomic reactivity at different motivational levels under verbal test. Journal of Russian and East European Psychology.

Dawson, M.E., Filion, D.L., \& Schell, A.M. (1989). Is the elicitation of the orienting response associated with the allocation of resources? Psychophysiology, 26, 560-572.

Dawson, M.E., Schell, A.M., \& Filion, D.L. (1990). The electrodermal system. In J.T. Cacioppo \& L.G. Tassinary (Eds.), Principles of psychophysiology. Cambridge: Cambridge University Press, pp. 295-324.

Dawson, M.E., Nuechterlein, K.H., Schell, A.M., Gitlin, M., \& Ventura, J. (1994). Autonomic abnormalities in schizophrenia: State or trait indicators? Archives of General Psychiatry, 51, 813-824.

De Marinis, M., Strano, S., Granata, M., Urani, C., Lino, S., Calcagnini, G., Di Virgilio, V., \& Calcagnini, G. (1995). Sympathetic-parasympathetic activation during spontaneous attacks of cluster headache: evaluation by spectral analysis of heart-rate fluctuations. Cephalalgia, 15, 504-510.

Filion, D.L., Dawson, M.E., \& Schell, A.M. (1994). Probing the orienting response with startle modification and secondary reaction time. Psychophysiology, 31, 68-78. 
Filion, D.L., Dawson, M.E., Schell, A.M., \& Hazlett, E.A. (1991). The relationship between skin conductance orienting and the allocation of processing resources. Psychophysiology, 28, 410-425.

Gregory, R.L. (1972). Cognitive contours. Nature, 238, 51-52.

Guyton, A.C. (1981). Textbook of medical physiology, W.B. Saunders, Philadelphia.

Hugdahl, K. (1996). Cognitive influences on human autonomic nervous system function. Current Opinion in Neurobiology, 6, 252-258.

Kagan, J., Reznick, J., \& Snidman, N. (1988). Biological bases of childhood shyness. Science, 240, 167-171.

Kalsbeek, J.W.H. (1973). Do you believe in sinus arrhythmia? Ergonomics, 16, 99-104.

Katkin, E.S. (1975). Electrodermal lability: A psychophysiological analysis of individual differences in response to stress. In I.G. Sarason \& C.D. Spielberger (Eds.), Stress and anxiety. Washington, DC: Aldine, Vol. 2, pp. 141-176.

Kronholm, E., Hyypps, M.T., Jula, A., \& Toikka, T. (1996). Electrodermal lability and hypertension. International Journal of Psychophysiology, 23, 129-136.

Lacey, J.I. (1959). Psychophysiological approaches to the evaluation of psychotherapeutic process and outcome. In E.A. Rubinstein \& M.B. Parloff (Eds.), Research in psychotherapy. Washington, D.C.: American Psychological Association.

Lacey, J.I., Kagan, J., Lacey, B.S., \& Moss, H.A. (1963). The visceral level: Situational determinants and behavioral correlates of autonomic response patterns. In P.H. Knapp (Ed.), Expression of the emotions in man. New York: International Universities Press, pp. 161-196.

Lukatela, G., Turvey, M., \& Todorovic, D. (1991). Is alphabet biasing in bialphabetical word perception automatic and prelexical? Journal of Experimental Psychology: Learning, Memory, \& Cognition, 17, 653-663.

MacDowell, K.A., \& Mandler, G. (1989). Constructions of emotion: Discrepancy, arousal, and mood. Motivation and Emotion, 13, 105-124. 
Mathews, A.M., \& Lader, M.H. (1971). An evaluation of forearm blood flow as a physiological measure. Psychophysiology, 8, 509-524.

Matthews, K.A., Woodall, K.L., \& Stoney, C.M. (1990). Changes in and stability of cardiovascular responses to behavioral stress: Results from a four-year longitudinal study of children. Child Development, 61, 1134-1144.

Mesherski, R.M. (1982). [Retroactive events in visual system]. Psikhologicheski zhurnal, 3, 141-150. (In Russian).

Moshkevich, V.S. (1970). Photoplethysmographia, Moscow: Medicina. (In Russian).

Mulder, G., \& Mulder, L.G.M. (1981). Information processing and cardiovascular control. Psychophysiology, 18, 392-402.

Munro, L.L., Dawson, M.E., Schell, A.M., \& Sakai, L.M. (1987). Electrodermal lability and rapid performance decrement in a degraded stimulus continuous performance task. Journal of Psychophysiology, 1, 249-257.

Okada, F., Tokumitsu, Y., Hoshi, Y., and Tamura, M., (1994). Impaired interhemispheric integration in brain oxygenation and hemodynamics in schizophrenia. European Archives of Psychiatry and Clinical Neuroscience, 244, 17-25

Paller, K., \& Shapiro, D. (1983). Systolic blood pressure and a simple reaction time task. Psychophysiology, 20, 585-589.

Papillo, J.F., \& Shapiro, D. (1990). The cardiovascular system. In J.T. Cacioppo \& L.G. Tassinary (Eds.), Principles of psychophysiology: Physical, social, and inferential elements. Cambridge: Cambridge University Press, pp. 465-512.

Paus, T., Zatorre, R.J., Hofle, N., Caramanos, Z., Gotman, J, Petrides, M., \& Evans, A.C. (1997). Time-related changes in neural systems underlying attention and arousal during the performance of an auditory vigilance task. Journal of Cognitive Neuroscience, 9, 392-408. 
Polich, J., McCarthy, G., Wang, W.S., \& Donchin, E. (1983). When words collide: orthographic and phonological interference during word processing. Biological Psychology, 16, 155-180.

Porges, S.W. (1980). Individual differences in attention. A possible physiological substrate. In B.K. Keogh (Ed.), Advances in special education. Greenwich, CT: JAI Press, Vol. 2, pp. 111-134.

Porges, S.W. (1992). Autonomic regulation and attention. In B.A. Campbell, H. Hayne, \& R. Richardson (Eds.), Attention and information processing in infants and adults. Hillsdale, NJ: Erlbaum, pp. 201-223.

Porges, S.W. (1995). Orienting in a defensive world: Mammalian modifications of our evolutionary heritage. A polyvagal theory. Psychophysiology, 32, 301-318.

Schell, A.M., Dawson, M.E., \& Filion, D.L. (1988). Psychophysiological correlates of electrodermal lability. Psychophysiology, 25, 619-632.

Schlapfer, T.E., Groner, M., Lavoyer, E., \& Fisch, H.U. (1991). Visual masking: a reliable measure for the assessment of cognitive dysfunction in the elderly? Journal of Gerontology, 46, 157-161.

Skolnick, B.E., Walrath, L.C., \& Stern, J.A. (1979). Evaluation of temporal vasomotor components of orienting and defensive responses. In H.D. Kimmel, E.H. van Olst, \& J.F. Orlebeke (Eds.), The orienting reflex in humans. Hillsdale, New Jersey, pp. 269276.

Smith, T.W., Houston, B.K., \& Zurawski, R.M. (1984). Finger pulse volume as a measure of anxiety in response to evaluative threat. Psychophysiology, 21, 260-264.

Smith, T.W., Nealey, J.B., Kircher, J.C., \& Limon, J.P. (1997). Social determinants of cardiovascular reactivity: Effects of incentive to exert influence and evaluative threat. Psychophysiology, 34, 65-73. 
Snieder, H., Boomsma, D.I., Van Doornen, L.J.P., \& De Geus, E.J.C. (1997). Heritability of respiratory sinus arrhythmia: Dependency on task and respiration rate. Psychophysiology, 34, 317-328.

Stone, L.W., \& Hokanson, J.E. (1969). Arousal reduction via self-punitive behavior. Journal of Personality and Social Psychology, 12, 72-79.

Suess, P.E., Porges, S.W., \& Plude, D.J. (1994). Cardiac vagal tone and sustained attention in school-age children. Psychophysiology, 31, 17-22.

Turpin, G., \& Siddle, D.A.T. (1983). Effects of stimulus intensity on cardiovascular activity. Psychophysiology, 20, 611-624.

Turpin, G. (1986). Effects of stimulus intensity on autonomic responding: The problem of differentiating orienting and defense reflexes. Psychophysiology, 23, 1-14.

Weber, E.J.M., Van der Molen, M.W., \& Molenaar, P.C.M. (1994). Heart rate and sustained attention during childhood: Age changes in anticipatory heart rate, primary bradycardia, and respiratory sinus arrhythmia. Psychophysiology, 31, 164-174.

Wolford, G., Marchak, F., \& Hughes, H. (1988). Practice effects in backward masking. Journal of Experimental Psychology: Human Perception \& Performance, 14, 101112. 
Table 1. Mean (SD) of Visual Tasks and Autonomic Measures in 37 Female and 17 Male Subjects.

\begin{tabular}{|c|c|c|c|c|c|c|c|c|c|c|}
\hline \multirow[b]{2}{*}{ Gender } & \multicolumn{2}{|c|}{ Visual Tasks } & \multicolumn{4}{|c|}{ Pulse Rate } & \multicolumn{4}{|c|}{ Pulse Volume } \\
\hline & VVT & $\mathrm{ATT}$ & PRb & PRi & PR1 & PR2 & $\mathrm{PVb}$ & PVi & PV1 & PV2 \\
\hline Female & $\begin{array}{c}90.38 \\
(61.89)\end{array}$ & $\begin{array}{c}0.51^{*} \\
(0.33)\end{array}$ & $\begin{array}{c}69.69 \\
(13.79)\end{array}$ & $\begin{array}{l}81.50^{* *} \\
(16.71)\end{array}$ & $\begin{array}{c}79.11^{* *} \\
(14.75)\end{array}$ & $\begin{array}{l}\text { 76.81*** } \\
(11.83)\end{array}$ & $\begin{array}{c}2365.11 \\
(1099.72)\end{array}$ & $\begin{array}{l}1965.69 \\
(984.76)\end{array}$ & $\begin{array}{c}2556.09 \\
(1173.46)\end{array}$ & $\begin{array}{c}2600.72 \\
(1154.66)\end{array}$ \\
\hline Male & $\begin{array}{c}80.00 \\
(43.59)\end{array}$ & $\begin{array}{c}0.34^{*} \\
(0.38)\end{array}$ & $\begin{array}{c}63.56 \\
(11.65)\end{array}$ & $\begin{array}{l}\text { 70.34** } \\
(14.76)\end{array}$ & $\begin{array}{l}67.92^{* *} \\
(16.45)\end{array}$ & $\begin{array}{l}67.23^{* * *} \\
(12.59)\end{array}$ & $\begin{array}{l}2423.35 \\
(729.54)\end{array}$ & $\begin{array}{l}2114.90 \\
(841.75)\end{array}$ & $\begin{array}{l}2397.66 \\
(837.00)\end{array}$ & $\begin{array}{l}2387.87 \\
(905.27)\end{array}$ \\
\hline
\end{tabular}

${ }^{*} p<.10 ; * * p<.05 ; * * * p<.01$. 
Table 2. Mean (SD) of Visual Task and Autonomic Measures in High $(N=25)$ and Low $(N=29)$ Stress Conditions.

\begin{tabular}{|c|c|c|c|c|c|c|c|c|c|c|}
\hline \multirow[b]{2}{*}{ Stress } & \multicolumn{2}{|c|}{ Visual Task } & \multicolumn{4}{|c|}{ Pulse Rate } & \multicolumn{4}{|c|}{ Pulse Volume } \\
\hline & VVT & ATT & $\mathrm{PRb}$ & PRi & PR1 & PR2 & $\mathrm{PVb}$ & $\mathrm{PVi}$ & PV1 & PV2 \\
\hline Low & $\begin{array}{l}76.55^{* *} \\
(44.74)\end{array}$ & $\begin{array}{l}0.36^{* *} \\
(0.38)\end{array}$ & $\begin{array}{c}70.45 \\
(15.24)\end{array}$ & $\begin{array}{c}78.52 \\
(18.92)\end{array}$ & $\begin{array}{c}74.47 \\
(18.02)\end{array}$ & $\begin{array}{c}73.02 \\
(14.26)\end{array}$ & $\begin{array}{c}2497.23 \\
(1045.52)\end{array}$ & $\begin{array}{l}\text { 2211.98* } \\
\text { (951.67) }\end{array}$ & $\begin{array}{c}2586.42 \\
(1027.99)\end{array}$ & $\begin{array}{c}2641.65 \\
(1070.00)\end{array}$ \\
\hline High & $\begin{array}{l}111.20^{* *} \\
(64.57)\end{array}$ & $\begin{array}{l}0.56^{* *} \\
(0.29)\end{array}$ & $\begin{array}{c}64.64 \\
(10.20)\end{array}$ & $\begin{array}{c}77.37 \\
(14.36)\end{array}$ & $\begin{array}{c}76.88 \\
(13.61)\end{array}$ & $\begin{array}{c}74.69 \\
(11.02)\end{array}$ & $\begin{array}{l}2251.45 \\
(928.14)\end{array}$ & $\begin{array}{l}1781.45 * \\
(881.75)\end{array}$ & $\begin{array}{c}2413.16 \\
(1138.00)\end{array}$ & $\begin{array}{c}2408.51 \\
(1096.41)\end{array}$ \\
\hline
\end{tabular}

${ }^{*} p<.10 ; * * p<.05$ 
Table 3. Mean (SD) of Visual Task and Autonomic Measures as a Function of Baseline Sympathetic/Parasympathetic (ANS) Grouping (1x1, $1 \times 2,2 \times 1,2 \times 2)$; «1»= High, «2»= Low).

\begin{tabular}{|c|c|c|c|c|c|c|c|c|c|c|c|}
\hline \multirow[b]{2}{*}{ Grouping } & \multirow[b]{2}{*}{$\mathrm{N}$} & \multicolumn{2}{|c|}{ Visual Task } & \multicolumn{4}{|c|}{ Pulse Rate } & \multicolumn{4}{|c|}{ Pulse Volume } \\
\hline & & VVT & ATT & $\mathrm{PRb}$ & Pri & PR1 & PR2 & $\mathrm{PVb}$ & $\mathrm{PVi}$ & PV1 & PV2 \\
\hline 1: $1 \mathrm{x} 1$ & 10 & $\begin{array}{l}116.00^{* *} \\
(83.16)\end{array}$ & $\begin{array}{c}0.50^{*} \\
(0.31)\end{array}$ & $\begin{array}{l}56.45 \\
(5.22)\end{array}$ & $\begin{array}{c}68.23 \\
(\mathbf{1 0 . 5 5 )}\end{array}$ & $\begin{array}{l}65.47 \\
(7.84)\end{array}$ & $\begin{array}{l}64.93 \\
(6.42)\end{array}$ & $\begin{array}{l}1877.46 \\
(239.25)\end{array}$ & $\begin{array}{l}1423.37 \\
(397.14)\end{array}$ & $\begin{array}{l}1905.98 \\
(352.28)\end{array}$ & $\begin{array}{l}1958.74 \\
(361.69)\end{array}$ \\
\hline $2: 1 x 2$ & 17 & $\begin{array}{c}69.41 \\
(40.07)\end{array}$ & $\begin{array}{c}0.25 \\
(0.40)\end{array}$ & $\begin{array}{l}78.56^{* * *} \\
(12.76)\end{array}$ & $\begin{array}{l}89.30 * * * \\
(16.06)\end{array}$ & $\begin{array}{l}86.86^{* * *} \\
(14.08)\end{array}$ & $\begin{array}{l}82.60 * * * \\
(10.56)\end{array}$ & $\begin{array}{l}1542.63 \\
(436.87)\end{array}$ & $\begin{array}{l}1334.24 \\
(477.98)\end{array}$ & $\begin{array}{l}1726.06 \\
(517.69)\end{array}$ & $\begin{array}{l}\text { 1828.18 } \\
\text { (584.39) }\end{array}$ \\
\hline 3: 2x1 & 15 & $\begin{array}{c}90.67 \\
(48.32)\end{array}$ & $\begin{array}{l}0.54^{* * * *} \\
(0.33)\end{array}$ & $\begin{array}{l}57.48 \\
(5.53)\end{array}$ & $\begin{array}{l}65.50 \\
(9.38)\end{array}$ & $\begin{array}{l}63.92 \\
(8.55)\end{array}$ & $\begin{array}{l}64.57 \\
(7.72)\end{array}$ & $\begin{array}{l}3203.81^{* * *} \\
(1086.49)\end{array}$ & $\begin{array}{l}\text { 2715.19*** } \\
(1064.41)\end{array}$ & $\begin{array}{l}3144.92^{* * *} \\
(1223.84)\end{array}$ & $\begin{array}{l}\text { 3024.23*** } \\
(1266.61)\end{array}$ \\
\hline 4: $2 \mathrm{x} 2$ & 12 & $\begin{array}{l}108.33^{*} \\
(50.57)\end{array}$ & $\begin{array}{l}0.60 * * * \\
(0.21)\end{array}$ & $\begin{array}{l}74.73^{* * * *} \\
(8.23)\end{array}$ & $\begin{array}{l}85.68 * * * \\
(14.93)\end{array}$ & $\begin{array}{l}82.64^{* * * *} \\
(16.65)\end{array}$ & $\begin{array}{l}80.22 * * * \\
(12.71)\end{array}$ & $\begin{array}{l}2970.80 * * * \\
(538.00)\end{array}$ & $\begin{array}{l}2586.66 * * * \\
(514.96)\end{array}$ & $\begin{array}{l}3313.23^{* * *} \\
(787.13)\end{array}$ & $\begin{array}{l}3399.22 * * * \\
(861.69)\end{array}$ \\
\hline
\end{tabular}

${ }^{*} p<.10 ; * *<.05 ; * * * p<.01$, comparing bold and non-bold scores. (Comparison of Contrasts). 